\title{
Erysipelothrix rhusiopathiae'nın etken olduğu nadir bir osteomiyelit olgusu
}

\author{
Tuğba Ayhanc1 ${ }^{1}$, Hüseyin Agah Terzi ${ }^{2}$, Mehmet Köroğlu ${ }^{1}$, Alper Erkin ${ }^{3}$, Mustafa Altındiş ${ }^{1}$
}

\begin{abstract}
$\ddot{\mathbf{O} z}$
Erysipelothrix rhusiopathiae doğada yaygın olarak bulunan hareketsiz, sporsuz, fakültatif anaerob, gram pozitif basildir. İnsanlarda nadiren hastalık yapar ve genellikle meslek hastalığ ile ilişkili olarak lokalize deri enfeksiyonları şeklinde görülür. Ortopedik literatürde nadiren enfeksiyon etkeni olduğundan bahsedilse de son on yıldaki raporlar, E. rhusiopathiae'nin reaktif artrit, osteomiyelit, prostetik enfeksiyon ve spondilit için bakteriyel etkenlerden biri olarak kabul edildiğini göstermektedir. Bu olgu sunumunda diabet ve hipertansiyonu bulunan hastada E. rhusiopathiae'nın etken olduğu osteomiyelit vakası sunulmaktadır. Tip 2 diabetes mellitus ve hipertansiyonu olan 65 yaşında kadın hasta üç ay öncesinde sağ ayak topuğu medial bölgesinde hatırlayamadığı şekilde ortaya çıkan ve iyileşmeyen yara nedeni ile yara bakım birimine yönlendirildi. Radyolojik olarak hastanın direkt grafisinde yaranın bulunduğu bölge altındaki kemik dokularda osteomiyelit ile uyumlu görünüm izlendi. Debridman sonrası hastadan alınan kemik doku kültüründe 48 saat sonra üreyen bakterinin kütle spektrofotometresi (VITEK MS, bioMerieux, Fransa) ile identifikasyonu sonucunda $E$. rhusiopathiae olduğu saptand. Bir ay süre ile intramüsküler yoldan 3 X1500 mg/gün ampisilin-sulbaktam tedavisi sonrası hastada iyileşme görüldü.
\end{abstract}

Yayın Bilgisi

Anahtar Kelimeler: Erysipelothrix rhusiopathiae, zoonoz, meslek hastalığı, yumuşak doku bozukluğu, osteomiyelit

\section{A rare case of osteomyelitis caused by erysipelothrix rhusiopathiae}

Tuğba Ayhanc ${ }^{1}$, Hüseyin Agah Terzi ${ }^{2}$, Mehmet Köroğlu ${ }^{1}$, Alper Erkin ${ }^{3}$, Mustafa Altındiş ${ }^{1}$

\begin{abstract}
Erysipelothrix rhusiopathiae is a nonmotile, nonspore-forming, facultative anaerobic, gram positive rod commonly found in nature. It rarely causes disease in humans and usually occurs as localized skin infections associated with occupational disease. Although E. rhusiopathiae is mentioned as a rare infection agent in orthopedic literature, the reports of the last decade show that is considered to be one of the bacterial agent for reactive arthritis, osteomyelitis, prosthetic infection and spondylitis. In this case report, we present a case of osteomyelitis which is caused by E. rhusiopathiae in a patient with diabetes mellitus and hypertension. A 65 -year-old woman with type 2 diabetes and hypertension was referred to the wound care unit with a wound that occured with an unknown reason three months before. Radiologically, direct gross appearance of the patient showed osteomyelitis-compatible appearance in the bone tissues beneath the wound-compatible region. E. rhusiopathiae was identified as a result of mass spectrophotometry after 48 hours in the bone tissue culture taken from the patient after debridement. Patient recovered with the completion of the treatment ampicillin-sulbactam $1 \mathrm{X} 500 \mathrm{mg} /$ day intramuscularly.
\end{abstract}

Gönderi Tarihi:13.06.2018

Kabul Tarihi:25.09.2018

Online Yayın Tarihi:31.12.2018

DOI: $10.26453 /$ otjhs.433710

Sorumlu Yazar

Tuğba AYHANCI

Keywords: Erysipelothrix rhusiopathiae, zoonoses, occupational disease, soft tissue disorder, osteomyelitis

\footnotetext{
${ }^{1}$ Sakarya Üniversitesi Tıp Fakültesi, Tıbbi Mikrobiyoloji Anabilim Dalı, Sakarya

${ }^{2}$ Sakarya Üniversitesi Eğitim ve Araştırma Hastanesi, Tıbbi Mikrobiyoloji Laboratuvarı, Sakarya

${ }^{3}$ Sakarya Üniversitesi Tıp Fakültesi, Kalp Damar Cerrahisi Anabilim Dalı, Sakarya
}

\section{GiRiş}

Erysipelothrix. rhusiopathiae, eski adıla $E$. insidiosa ilk defa Koch tarafından izole edilmiş olup; $\quad 0,2-0,4 \mu \mathrm{m}$ eninde ve $0,8-2,5 \mu \mathrm{m}$ uzunluğunda, hareketsiz, sporsuz gram pozitif basildir. ${ }^{1}$ Ancak bu bakteri çok hızlı dekolorize olabildiği için Gram negatif boyanabilmektedir. ${ }^{2}$ Bakteri, çeşitli biyokimyasal özelliklerinin yanı sira; katalaz (-) ve $\mathrm{H}_{2} \mathrm{~S}$ üreten tek Gram pozitif basil olması ile tanımlanmaktadır. ${ }^{3}$

İnsanlarda başlıca üç klinik şekilde hastalığa neden olur. Bunlar; erizipeloid olarak 
isimlendirilen lokalize deri enfeksiyonu, yaygın deri enfeksiyonu ve genellikle endokardit ile seyreden bakteriyemi şeklindedir. ${ }^{4,5}$ Ayrıca; beyin apsesi, menenjit, epidural apse, paravertebral apsesi, endoftalmi, pnömoni, osteomiyelit, septik artrit, prostetik eklem enfeksiyonu, nekrotizan fasiit, karaciğer apsesi, intraabdominal abse ve peritonit gibi fokal enfeksiyonlar da nadir olarak bildirimi yapılmış enfeksiyonlardır., ${ }^{4,-12}$

$\mathrm{Bu}$ olgu sunumunda E.rhusiopathiae suşunun etken olduğu bir osteomiyelit vakas1 sunulmaktadır.

\section{OLGU}

65 yaşında kadın hasta üç ay önce sağ ayak topuğunda hatırlayamadığı bir şekilde ortaya çıkan ve iyileşmeyen bir yara nedeniyle hastanemiz yara bakım birimine yönlendirildi. Muayenede sağ ayak topuk medialinde yaklaşı $3 \times 2 \mathrm{~cm}$, yüzeyi nekrotik görünümlü yara olduğu gözlendi. Hasta obez ve bacaklar ödemli görünümde idi. Ayrıca hastanın özgeçmişinde Tip 2 Diabetes Mellitus ve hipertansiyon bulunmaktaydi. Laboratuvar testlerinde; Lökosit sayısı: $8,53 \mathrm{~K} / \mu \mathrm{L}(4,6-10,2$ $\mathrm{K} / \mu \mathrm{L})$, Eritrosit sayıs1: $3,87 \mathrm{M} / \mu \mathrm{L} \quad(4,04-$ $6,13 \mathrm{M} / \mu \mathrm{L})$, Hemoglobin: 10,2g/dL (12,218,1g/dL), Hematokrit: 32,9\% (37,7- 57,7\%), C Reaktif Protein: 46,4mg/L (0-0,5mg/L), Glukoz: $131 \mathrm{mg} / \mathrm{dL}$ (70-100 mg/dL), Üre:91mg/dL (1743mg/dL), Kreatinin: $1,36 \mathrm{mg} / \mathrm{dL} \quad(0,67-$ 1,17mg/dL), Albumin: 3,1g/dL (3,2-4,6g/dL), Sedimantasyon: $\quad 95 \mathrm{~mm} / \mathrm{saat} \quad(<30 \mathrm{~mm} / \mathrm{saat})$ bulundu. Radyolojik olarak hastanın direkt grafisinde yaranın bulunduğu bölge altındaki kemik dokularda osteomiyelit ile uyumlu görünüm izlendi. Hastaya cerrahi debridman planlandi. Hasta bir hafta süre ile sefaleksin 1 X1gr/gün ve siprofloksasin 2X750mg/gün kullandı. Debridman sonrası hastadan alınan kemik doku örneği, bakteriyolojik açından değerlendirilmesi amacıyla işleme alındı. Kemik dokunun Gram boyamasında çok sayıda polimorfonükleer lökositler ve Gram pozitif basiller görüldü. Hastadan alınan doku; kanlı agar, çikolata agar ve eosin metilen mavisi (EMB) agara ekilerek, $35-37^{\circ} \mathrm{C}^{\prime} \mathrm{de}$ bir gece inkübasyona bırakıldı. Ertesi gün yetersiz üreme nedeniyle inkübasyon süresi 24 saat uzatıldı. İki gün sonra kanlı agar plaklarında küçük, beyaz koloniler ürediği gözlendi. İzole edilen bakterinin identifikasyonu $\quad$ VITEK $^{\circledR} \quad 2$ ve kütle spektrofotometresi ile (VITEK MS, bioMerieux, Fransa) yap1ld1 ve izolat E. rhusiopathiae olarak tanımlandı.

Antibiyotik duyarlılık testi CLSI kriterlerine göre gerçekleştirildi. Test sonucunda bakterinin penisilin dirençli; imipenem, eritromisin, tetrasiklin, sefotaksim, siprofloksasin duyarlı olduğu bulundu. Bir ay süreyle intramüsküler yoldan 3X1500mg/gün ampisilin-sulbaktam tedavisi sonrası tamamen iyileşme görüldü. Hastanın daha sonraki kontrollerinin de normal sınırlarda olduğu saptandi.

\section{SONUC}

E.rhusiopathiae doğada yaygın olarak bulunan hareketsiz, sporsuz, fakültatif anaerob, gram 
pozitif basildir. Domuz, balık ve kuş gibi birçok omurgalı hayvan bu bakterinin doğal rezervuarıdır. İnsanda nadiren hastalık yapar ve genellikle meslek hastalığı şeklinde veteriner, balıkçı, kasap ve çiftçilerde görülür. ${ }^{3,5,13}$ Tan ve ark. çalışmalarında hayvan maruziyeti dışında immünsupresyon, diabetes mellitus ve böbrek hastalığının da risk faktörleri arasında olduğunu bildirmiştir. ${ }^{14}$ Bizim olgumuzda etkenin meslek hastalığı ile ilişkili olmadığı anlaşılmakla beraber hastada bulunan diyabet mellitus tip 2 tanıs1 enfeksiyona yatkınlığı düşündürmektedir. İnsanlara bulaş genellikle hayvan ürünleriyle kontamine aletlerin cildi delmesiyle olur ve tipik olarak erizipeloid tarzda enfeksiyon ortaya çıkar. Ortopedik literatürde nadiren enfeksiyon etkeni olduğundan bahsedilmektedir. ${ }^{15}$ Ancak literatürde osteomiyelit vaka sayısı oldukça az olsa da son on y1ldaki raporlar, E.rhusiopathiae reaktif artrit ${ }^{16}$, osteomiyelit ${ }^{16}$, prostetik enfeksiyon ${ }^{10}$ ve spondilit ${ }^{6}$ için bakteriyel etkenlerden biri olarak kabul edildiğini $\quad$ göstermektedir. ${ }^{17}$ E.rhusiopathiae suşları penisilin, sefalosporin, eritromisin, klindamisine yüksek oranda duyarlılık gösterirler. ${ }^{18-20} \mathrm{Bu}$ sebeple penisilin, sefalosporinler, florokinolonlar ve linkozamidler E.rhusiopathiae enfeksiyonlarına karşı tedavide kullanılan temel antibiyotiklerdir. ${ }^{15}$ Ancak birçok yayında bakterinin penisiline duyarlı olduğu bildirilmesine rağmen bizim vakamızda penisiline dirençli e.rhusiopathiae izole edilmesi dikkat çekicidir. Bakterinin kloromfenikol ve tetrasiklinlere duyarlılık oranlarının giderek değiştiğini rapor eden yayınlar vardır. ${ }^{20}$ Trimethoprim Sulfamethoxazol, sülfonamid, aminoglikozid, vankomisin, novobiyosin ve polimiksinler ise bakterinin doğal direnç gösterdiği antibiyotiklerdir. ${ }^{21} \mathrm{Bu}$ olguda hastaya ampirik olarak sefaleksin 1X1 gr/gün ve siprofloksasin $2 \times 750 \mathrm{mg} /$ gün tedavisi başlandı. Ancak bakteri kinolon ve sefalosporinlere in vitro duyarlı olsa da bu antibiyotiklerin in vivo etkinliği yeterli olmayabileceği için ampisilin sulbaktam ile revize edildi. Penisilinlere direnç büyük oranda bakteride bulunan beta-laktamaz enzim aktivitesi ile gerçekleşmektedir. Bu bilgi göz önüne alınarak tedavide bir beta-laktamaz inhibitörü olan sulbaktam ve ampisilin kombinasyonu bir ay süreyle intramüsküler yoldan $3 X 1500 \mathrm{mg} /$ gün uygulanarak tedavide başarı sağlandı. Osteomiyelit, reaktif artrit, prostetik enfeksiyon ve spondilit gibi enfeksiyonlarda e.rhusiopathiae'nın da etken olabileceği akılda tutulmalı ve özellikle ampirik tedavi verirken bu bakteri de dikkate alınmalıdır. Ayrıca antibiyotik duyarlılık testi yapılmalı ve gerektiğinde tedavi buna göre revize edilmelidir.

\section{KAYNAKLAR}

1. Koch R, Cheyne WW. Investigations into the etiology of traumatic infective diseases. London: New Sydenham Society Publications; 1880.

2. MicrobeWiki. Erysipelothrix. https://microbewiki.kenyon.edu/index.php/Ery sipelothrix (Erişim: 01.06.2018)

3. Venditti M, Gelfusa V, Castelli F, Brandimarte C, Serra P. Erysipelothrix rhusiopathiae 
endocarditis Eur J Clin Microbiol Infect Dis. 1990;1:50-2.

4. Grieco MH, Sheldon C. Erysipelothrix rhusiopathiae. Ann NY Acad Sci. 1970; 174: 523-532.

5. Robson JM, McDougall R, van der Valk S, Waite SD, Sullivan JJ. Erysipelothrix rhusiopathiae: An uncommon but ever present zoonosis Pathology. 1998; 30: 391-4.

6. Andrychowski J, Jasielski P, Netczuk T, Czernicki Z. Empyema in spinal canal in thoracicregion, abscesses in paravertebral space, spondylitis: in clinical course of zoonosis Erysipelothrix rhusiopathiae. EurSpine J. 2012; 21: S557-563.

7. Elvy J, Hanspal I, Simcock P. A case of Erysipelothrix rhusiopathiae causing bilateral endogenous endophthalmitis. J Clin Pathol. 2008; 61: 1223-1224.

8. Feasi M, Bacigalupo L, Cappato S, Pontali E, Usiglio D, Rollandi GA, Filauro M, Mori M, Cassola G. Erysipelothrix rhusiopathiae intraabdominal abscess. Int J Infect Dis. 2010; 14: e81-83.

9. Hardman SC, Carr SJ, Swann RA. Peritoneal dialysis-related peritonit is with bacteraemia due to Erysipelothrix rhusiopathiae. Nephrol Dial Transplant. 2004; 19: 1340-1341.

10. Hocqueloux L, Poisson DM, Sunder S, Guilbert S, Prazuck T. Septic arthritis caused by Erysipelothrix rhusiopathiae in a prosthetic kneejoint. J Clin Microbiol. 2010;48: 333-335.

11. Jones N, Khoosal M. Erysipelothrix rhusiopathiae septicemia in a neonate. Clin Infect Dis. 1997; 24: 511.

12. Kim SR, Kwon MJ, Lee JH, Lee NY. Chronic meningitis caused by Erysipelothrix rhusiopathiae. J Med Microbiol. 2007; 56: 1405-1406.
13. Norman B, Kihlstrom E. Erysipelothrix rhusiopathiae septicemia. Scand J Infect Dis. 1985; 17: 123-4

14. Tan EM, Marcelin JR, Adeel N, Lewis RJ, Enzler MJ, Tosh PK. Erysipelothrix rhusiopathiae bloodstream infection - A 22year experience at Mayo Clinic, Minnesota. 2017; 64(7): e65-e72.

15. K. Tolis, S. Spyridonos, S. Tsiplakou and E. Fandridis Tenosynovitis of a digit due to Erysipelothrix rhusiopathiae: case report and review of the literature New Microbes New Infect. 2015; 8: 128-130.

16. Mukhopadhyay C, Shah H, Vandana KE, Munim F, Vijayan S. A child with Erysipelothrix arthritis beware of the little known. AsianPac J Trop Biomed. 2012; 2: $503-$ 504.

17. Romney M, Cheung S, Montessori V. Erysipelothrix rhusiopathiae endocarditis and presumed osteomyelitis Can J Infect Dis. 2001; 12(4): 254-256.

18. Gorby GL, Peacock JE Jr. 1988. Erysipelothrix rhusiopathiae endocarditis: microbiologic, epidemiologic, and clinical features of an occupational disease. Rev. Infect. Dis. 10: 317325.

19. Heilman FR, Herrell WE. 1944. Penicillin in thetreatment of experimental infections due to Erysipelothrix rhusiopathiae. Proc. Staff Meet. Mayo. Clin. 19: 340-345.

20. Poretz DM. 1985. Erysipelothrix rhusiopathiae, p. 1185-1186. In G. L. Mandell, R. G. Douglas, Jr., and J. E. Bennett (ed.), Principles and practice of infectious diseases, 2nd ed. J. Wiley\&Sons, Inc., New York.

21. Reboli AC, Farrar WE. 1989 Erysipelothrix rhusiopathiae: An Occupational Pathogen. Clin Microbiol Rev. 1989; 2(4): 354-359. 


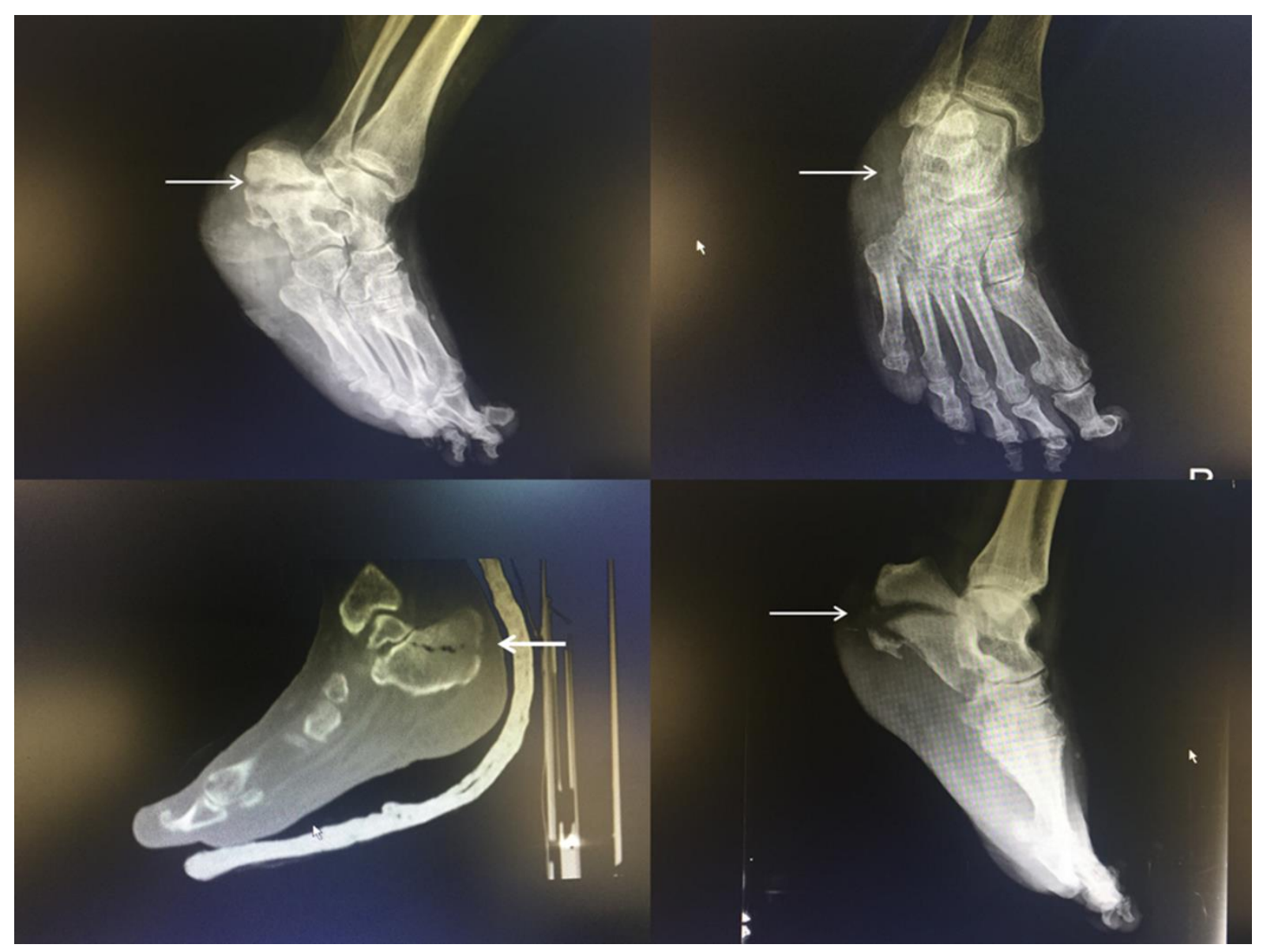

Şekil 1. Sağ ayakta görülen osteomyelitin radyolojik direkt grafi görüntüleri 